\title{
Safety and efficacy of extracorporeal shock wave lithotripsy for difficult-to- retrieve common bile duct stones: A ten-year experience
}

\author{
Muhammad Manzoor ul Haque, Nasir Hassan Luck, Abbas Ali Tasneem, Syed \\ Mudassir Laeeq, Rajesh Mandhwani, Farina M. Hanif, Ghulam Ullah Lail \\ Sindh Institute of Urology and Transplantation, Karachi, Sindh, Pakistan
}

Address for Correspondence:

Dr. Muhammad Manzoor ul Haque, Sindh Institute of Urology and Transplantation, Karachi, Sindh, Pakistan. E-mail: manzoorsiddiqui777@hotmail.com

\begin{tabular}{|l|}
\hline Access this article online \\
\hline $\begin{array}{l}\text { Website: } \\
\text { www.intern-med.com }\end{array}$ \\
\hline DOI: \\
10.2478/jtim-2020-0025 \\
\hline Quick Response Code: \\
\hline \\
\hline \\
\hline \\
\hline
\end{tabular}

\section{ABSTRACT}

Background and Objective: Extracorporeal shock wave lithotripsy (ESWL) for common bile duct (CBD) stones has been used in the past, but experience is limited. We report our experience of ESWL in the management of difficult CBD stones. Methods: Patients with difficult-to-retrieve CBD stones were enrolled and underwent ESWL. Fluoroscopy is used to target the stones after injection of contrast via nasobiliary drain. CBD clearance was the main outcome of the study. Results: Eighty-three patients were included (mean age $50.5 \pm 14.5$ years); these patients were mainly females $(43 ; 51.8 \%)$. Large stones $>15 \mathrm{~mm}$ were noted in $64(77.1 \%)$, CBD stricture in $22(26.5 \%)$ and incarcerated stone in $8(9.6 \%)$ patients. Patients needed $2.1 \pm 1.2$ sessions of lithotripsy and $4266 \pm 1881$ shock waves per session. In 75 (90.3\%) patients, the fragments were extracted endoscopically after ESWL, while spontaneous passage was observed in $8(9.6 \%)$. Total CBD clearance was achieved in $67(80.6 \%)$ patients, partial clearance in $5(6 \%)$ and no response in $11(13.2 \%)$. Failure of the treatment was observed in large stone with size $\geq 2 \mathrm{~cm}(P=0.021)$, incarcerated stone $(P=0.020)$ and pre-endoscopic retrograde cholangiopancreatography cholangitis $(P=$ 0.047). Conclusion: ESWL is a noninvasive, safe and effective therapeutic alternative to electrohydraulic lithotripsy and surgical exploration for difficult biliary stones.

Key words: difficult-to-retrieve biliary stone, extracorporeal shock wave lithotripsy (ESWL), nasobiliary drain

\section{INTRODUCTION}

Endoscopic removal of common bile duct (CBD) stones using balloon sweep or mechanical lithotripter after biliary sphincterotomy has been the standard of care for many decades. However, removing large $\mathrm{CBD}$ stones using these conventional methods has remained a therapeutic challenge. CBD clearance is achieved in $85 \%-90 \%$ of the cases using the standard technique, while in about $10 \%-15 \%$ cases, the extraction of stone remains challenging. ${ }^{[1,2]}$ Extracorporeal shock wave lithotripsy (ESWL) is emerging as a promising nonsurgical treatment option for removing large, difficult-to-retrieve, bile duct stones and has been tried in different centers of the world. ${ }^{[3-6]}$ Large
CBD stones (size $>15 \mathrm{~mm}$ ), intrahepatic stones, impacted stones in an altered CBD anatomy and those associated with the presence of biliary stricture are considered to be difficult-to-retrieve stones. When the conventional method of removing CBD stone has failed and the patient is unfit or not willing for the surgery, then various alternative techniques can be used including ESWL, electrohydraulic lithotripsy and laser lithotripsy. Chaussy et al. first described ESWL for the fragmentation of renal and ureteric stones in $1980 . .^{[3]}$ ESWL is a relatively simple, safe and effective technique for the removal of difficult CBD stones. In contrast, surgical exploration of $\mathrm{CBD}$ is associated with morbidity and mortality of about $1 \%$ in young and fit patients and as high as $9 \%-10 \%$ in elderly 
patients. ${ }^{[3,7]}$ Using ESWL for difficult-to-retrieve CBD stones yields complete clearance in about $85 \%$ of cases. ${ }^{[8-19]}$ Post-ESWL complications include abdominal pain, cholangitis, sepsis, pancreatitis, hematoma and hematuria, which lead to short-term morbidity in up to $14 \%$ of patients. ${ }^{[20]}$ Recurrence of stone has also been reported in up to $13 \%$ of patients within a follow-up period of 1 year. ${ }^{[20]}$ Mortality is reported to occur in about $1 \%$ of cases and is found to be related to advanced age, cholangitis and serious comorbid conditions. ${ }^{[18]}$

Here we report our experience of removing large, difficultto-retrieve CBD stones in our local population using ESWL during the past one decade. It is also aimed to assess the safety and effectiveness of the procedure and to identify procedure-related complications.

\section{PATIENTS AND METHODS}

This is a single-center study carried out in the Department of Gastroenterology at Sindh Institute of Urology and Transplantation. The study was approved by the institutional ethics committee, and ethical guidelines of the Declaration of Helsinki have been followed. ESWL was performed in all patients in whom the difficult CBD stone could not be retrieved during endoscopic retrog rade cholangiopancreatography (ERCP) by sphincterotomy, sphincteroplasty, balloon sweeps, mechanical lithotripsy or a combination of any of these procedures. Following the first ERCP, a nasobiliary drain was placed to localize the stone during ESWL.

A total of 83 patients with large CBD stones in the extrahepatic biliary tract that could not be removed by conventional endoscopic techniques underwent ESWL using Modulith SLX lithotripter. It generates electromagnetic shock waves, which were then focused onto the stone. Three-dimensional localization of the stone was carried out using fluoroscopic projection after injection of contrast via nasobiliary drain. Targeting of stones was achieved under fluoroscopic guidance.Before enrolling into the study, preliminary tests were performed, which included hematology, biochemistry, coagulation profile, pregnancy test, chest radiograph and ultrasound abdomen. Absolute contraindications for the treatment were a positive pregnancy test or irreversible coagulopathy, whereas abdominal aneurysm, vascular thrombosis, portal hypertension, cirrhosis, arrhythmia and renal failure were considered as relative contraindications for the procedure.

All the procedures were done in prone position under conscious sedation with short-acting benzodiazepine and opioid analgesic when needed. Supplemental oxygen at the rate of $2-4 \mathrm{~L} / \mathrm{min}$ was given, and electrocardiographic pulse oximetry monitoring was carried out during ESWL. Shock waves produced by electromagnetic induction were focused through a water cushion and hydrophilic gel on the skin to target the stones.

According to the tolerance of each patient, medium- to high-power energy (range 4-8) was used during ESWL. Shocks were given at the rate of 60 shocks per minute and a maximum of 7000 shocks were given per session. The end point of each session was optimal fragmentation of stones or maximum number of shocks, whichever occurred first.

In most of the cases, after adequate fragmentation $(<5 \mathrm{~mm})$ of stones by ESWL, a second ERCP was required for the removal of fragmented bile duct stones. However, in those patients in whom post-ESWL nasobiliary cholangiogram revealed stone clearance, they did not require a second ERCP and were considered as spontaneous clearance. The outcome was assessed by the clearance of CBD. Both early and late complications were noted. CBD stenting or a second session of ESWL was needed in the setting of partial clearance of CBD or when a CBD stricture was found to be present.

\section{Statistical analysis}

Statistical analysis was performed using SPSS version 22.0.0.0. Quantitative data such as age, stone size, alkaline phosphatase, gamma-glutamyl transferase, serum amylase and white blood cell counts were expressed as mean \pm standard deviation. Categorical variables such as gender, presence of fever, jaundice, cholangitis, biliary dilatation, right upper quadrant pain and clearance of stones were presented as frequencies and percentages. The chi-square or the Fisher exact test was used to identify the factors associated with satisfactory CBD clearance.

\section{RESULTS}

A total of 83 patients fulfilled the inclusion criteria and were treated by ESWL for CBD stones. The mean age of patients was $50.5 \pm 14.5$ years; the patients were predominantly females $(43 ; 51.8 \%)$. Indications for lithotripsy included large-sized stone of more than $15 \mathrm{~mm}$ in $64(77.1 \%)$, CBD stricture in $22(26.5 \%)$ and incarcerated stone in 8 $(9.6 \%)$ patients. At presentation, jaundice was present in, abdominal pain in 75 (90.4\%), fever in $63(75.9 \%)$ and patients (Table 1). Pre-ERCP pyrexia and cholangitis were present in $29(34.9 \%)$ and were treated with intravenous antibiotics before ESWL. Comorbid conditions were present in $26(31.3 \%)$ patients and included ischemic heart disease in 7 (8.4\%), diabetes mellitus in $12(14.5 \%)$, endstage renal disease in $5(6 \%)$ and chronic liver disease in 2 $(2.4 \%)$ patients. However, the procedure was well tolerated, and no immediate and late complications were observed. 


\begin{tabular}{lc}
\hline \multicolumn{2}{l}{ Table 1: Demographic and pre-ESWL clinical and } \\
biochemical features \\
\hline Clinical variables & $\boldsymbol{N}(\%)$ \\
\hline Age & $50.5 \pm 14.5$ \\
Gender (Male: Female) & $40(48.2 \%): 43(51.8 \%)$ \\
Co-morbid condition & $12(14.5 \%)$ \\
Diabetes mellitus & $5(6.0 \%)$ \\
Ischemic heart disease & $5(6 \%)$ \\
End stage renal disease & $2(2.4 \%)$ \\
Chronic liver disease & \\
Clinical presentation & $63(75.9 \%)$ \\
Jaundice & $35(42.2 \%)$ \\
Fever & $29(34.9 \%)$ \\
Cholangitis & $75(90.4 \%)$ \\
Right upper quadrant pain & \\
Pre ERCP ultrasonography & $76(91.6 \%)$ \\
Biliary dilatation & $61(73.5 \%)$ \\
CBD Stone or Sludge & $66(79.5 \%)$ \\
Gall bladder stone & $9(14.8 \%)$ \\
Prior cholecystectomy & \\
Biochemical characteristics & $1.63 \pm 0.53$ \\
Stone size (cm) & $5.3 \pm 6.1$ \\
TB (mg/dL) & $263 \pm 150$ \\
ALP (U/L) & $175.8 \pm 169$ \\
GGT (U/L) & $59.7 \pm 47.5$ \\
AST (U/L) & $54.7 \pm 54.9$ \\
ALT (U/L) & $0.17 \pm 0.37$ \\
Creatinine (mg/dL) & \\
\hline ESWL: & \\
\hline
\end{tabular}

ESWL: extracorporeal shock wave lithotripsy; ERCP: endoscopic retrograde cholangiopancreatography; $\mathrm{CBD}$ : common bile duct; TB: total bilirubin; ALP: alkaline phosphatase; GGT: gamma glutamyl trasferase; AST: aspartate aminotransferase; ALT: alanine aminotransferase.
Primary CBD stones were present in $9(10.8 \%)$ patients, all of whom had cholecystectomy prior to induction into the study. Stone size was $\geq 1.5 \mathrm{~cm}$ in $64(77.1 \%)$ patients. Incarcerated stones and CBD strictures were present in 8 $(9.6 \%)$ and $22(26.5 \%)$ patients, respectively. Single stone was present in 42 , while 41 patients had two or multiple stones.Most of the patients $56(67.3 \%)$ underwent an ESWL session immediately on the next day of ERCP, while in $27(30.6 \%)$ patients, the procedure was delayed for $3.21 \pm 3.6$ days due to various reasons that included postERCP cholangitis $(9 ; 10.8 \%)$, pancreatitis $(6 ; 7.2 \%)$, preERCP cholangitis $(4 ; 4.8 \%)$ and others $(3 ; 3.6 \%)$. A total of 178 ESWL sessions were performed in 83 patients. ESWL was carried out at a rate of 60 shocks per minute with an energy level of 4-6 kilojoules. Each patient underwent 2.14 \pm 1.20 sessions of ESWL until the stones were fragmented to $<5 \mathrm{~mm}$ (Figure 1). Per session, an average of $4266 \pm$ 1881 shocks was given. The majority of the patients (57; $68.6 \%$ ) required $\leq 2$ sessions of ESWL, after which a second ERCP was needed to extract stone fragments in 59 (71\%) patients, while spontaneous passage was observed in $8(9.6 \%)$ patients. Total CBD clearance was achieved in $67(80.6 \%)$ patients, partial CBD clearance in $5(6 \%)$ and failure of CBD clearance was seen in 11 (13.2\%); see Table 2. Failure of the treatment was observed in patients with large stone size $(\geq 2.0 \mathrm{~cm} ; P=0.021)$, presence of incarcerated stone $(P=0.020)$ and pre-ERCP cholangitis $(P=0.047)$ (Table 3$)$. A total of $7(8.4 \%)$ patients underwent $\mathrm{CBD}$ exploration including those in whom the

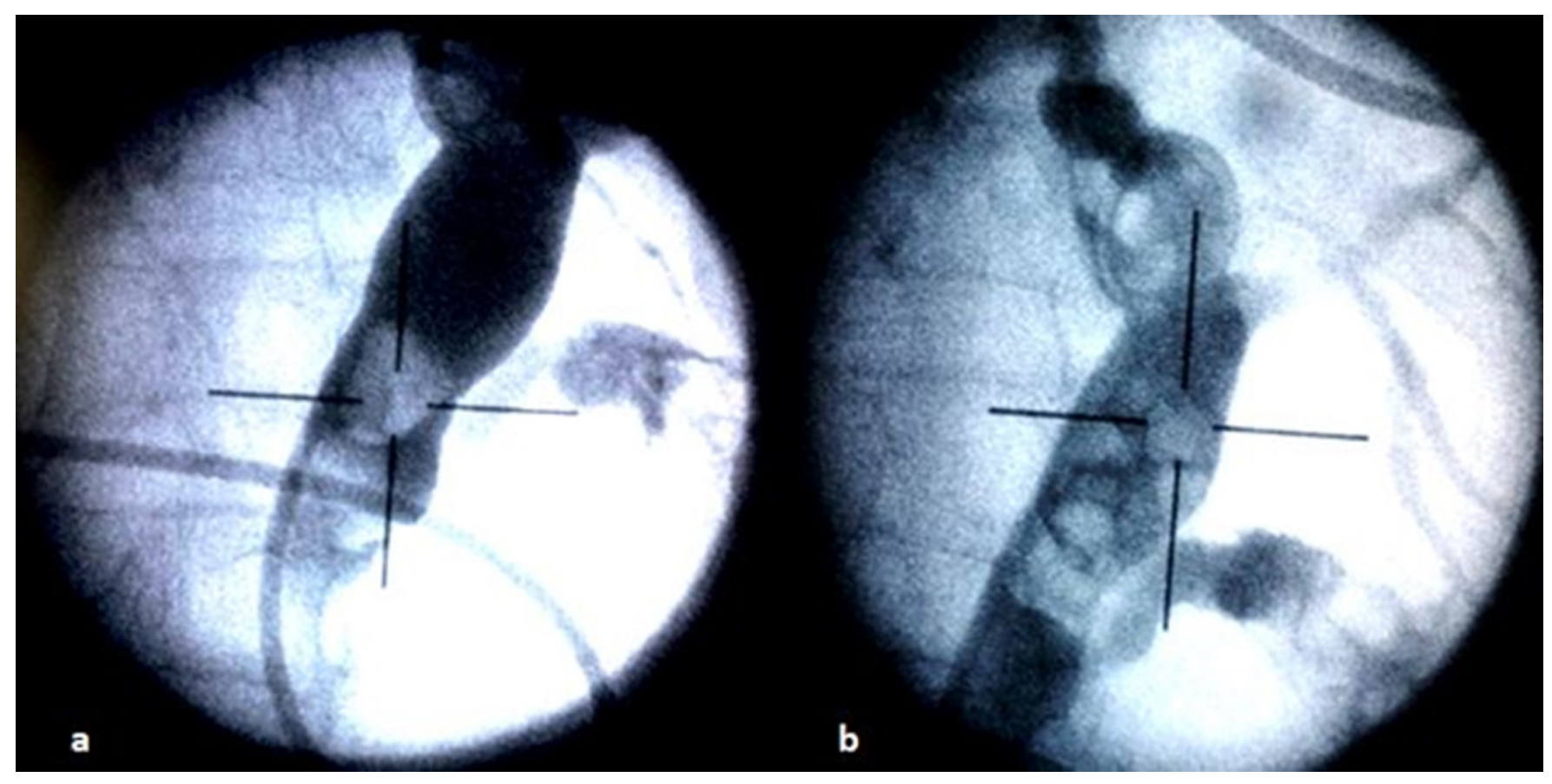

Figure 1: a) Showing delineated CBD stone following injection of contrast material; b) Showing post ESWL fragmentation of stone 


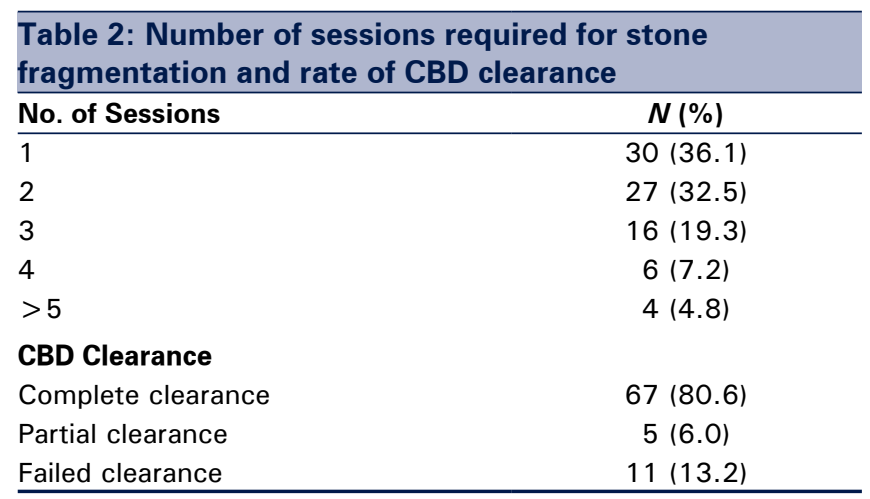

CBD: common bile duct.

endoscopic methods had failed $(5 ; 6.0 \%)$ or were found to be unsuitable for repeat endoscopic therapy $(2 ; 2.4 \%)$.

The most frequent side effects were transient microscopic hematuria in $11(13.3 \%)$, fever in $11(13.3 \%)$, hemobilia in 3 $(3.6 \%)$ and cholangitis in $9(10.8 \%)$ patients. The nasobiliary drain was displaced or removed by the patient in $6(7.2 \%)$ cases. The ESWL session could not be completed or had to be temporarily withheld in $15(18.1 \%)$ patients due to the development of complications (Figure 2). The total hospital stay was $9.6 \pm 4.8$ days. A prolonged hospital stay was required in those patients who needed multiple ESWL sessions. In some of these patients, a second ERCP was not required due to the achievement of spontaneous clearance.

Recurrence of stone was observed in 10 (11.9\%) patients, and most of these were the ones who had prior gall stones (odds ratio $=2.32$ ) and did not undergo cholecystectomy after discharge from hospital. Mortality related to or not to ESWL was not observed in any of the patients included in the study.

\section{DISCUSSION}

The role of ESWL in the treatment of urolithiasis is well recognized. ${ }^{[21]}$ It has also emerged as a promising technique for the removal of CBD stones that are not amenable to traditional extraction techniques. Many studies have reported variable success in treating difficult-to-retrieve bile duct stones with ESWL. ${ }^{[5,6,11]}$ Although the use of firstgeneration lithotripters has demonstrated better clearance rates compared to the second-generation machines (mean clearance rate $83 \%$ versus $72 \%$, respectively), the former is cumbersome as patients have to be immersed in a water bath. ${ }^{[12]}$ In this study, we report our 10 years' experience for treating difficult-to-retrieve CBD stones using the latest generation Modulith SLX extracorporeal lithotripter. Stone clearance was achieved in $80.6 \%$ of patients with difficult bile duct stones with a lower complication rate and morbidity compared to surgical CBD exploration. A similar clearance rate was reported by Tandan and Reddy, who also demonstrated that the procedure is well tolerated and has minimal side effects. ${ }^{[6]}$

Our study results suggest that ESWL is a safe, effective and well-tolerated treatment option for difficult CBD stones. All the cases were performed under conscious sedation; however, some patients required intravenous analgesics too. Accurate targeting of stones using fluoroscopy resulted in better outcomes and fewer complications. Important determinants of unsuccessful clearance were larger stone size, incarcerated stones and pre-ERCP cholangitis. These patients required multiple sessions or alternative treatment options. Spontaneous clearance of stones without the need of a second ERCP is possible but requires a longer duration of hospital stay and multiple sessions of ESWL. However,

\begin{tabular}{|c|c|c|c|c|}
\hline \multirow[b]{2}{*}{ Variables } & & \multicolumn{2}{|c|}{ Outcome of ESWL } & \multirow[b]{2}{*}{$P$ value } \\
\hline & & Unsatisfactory & Satisfactory & \\
\hline \multirow[t]{2}{*}{$\overline{\text { Age }}$} & $>50$ & 10 & 33 & 0.34 \\
\hline & $<50$ & 6 & 24 & \\
\hline \multirow[t]{2}{*}{ Pre ESWL raised WBC } & Yes & 9 & 20 & $0.047 *$ \\
\hline & No & 7 & 47 & \\
\hline \multirow[t]{2}{*}{ Co-morbidity } & Yes & 5 & 13 & 0.30 \\
\hline & No & 11 & 54 & \\
\hline \multirow[t]{2}{*}{ Stone size $>2.0 \mathrm{~cm}$} & Yes & 10 & 21 & $0.021 *$ \\
\hline & No & 6 & 46 & \\
\hline \multirow[t]{2}{*}{ Number of stones } & Single & 7 & 35 & 0.54 \\
\hline & Multiple & 9 & 32 & \\
\hline \multirow[t]{2}{*}{ Incarcerated stone } & Yes & 4 & 4 & $0.020 *$ \\
\hline & No & 12 & 63 & \\
\hline \multirow[t]{2}{*}{ CBD stricture } & Yes & 4 & 18 & 0.87 \\
\hline & No & 12 & 49 & \\
\hline
\end{tabular}

*Statistically significant. ESWL: Extracorporeal shock wave lithotripsy; CBD: common bile duct. 


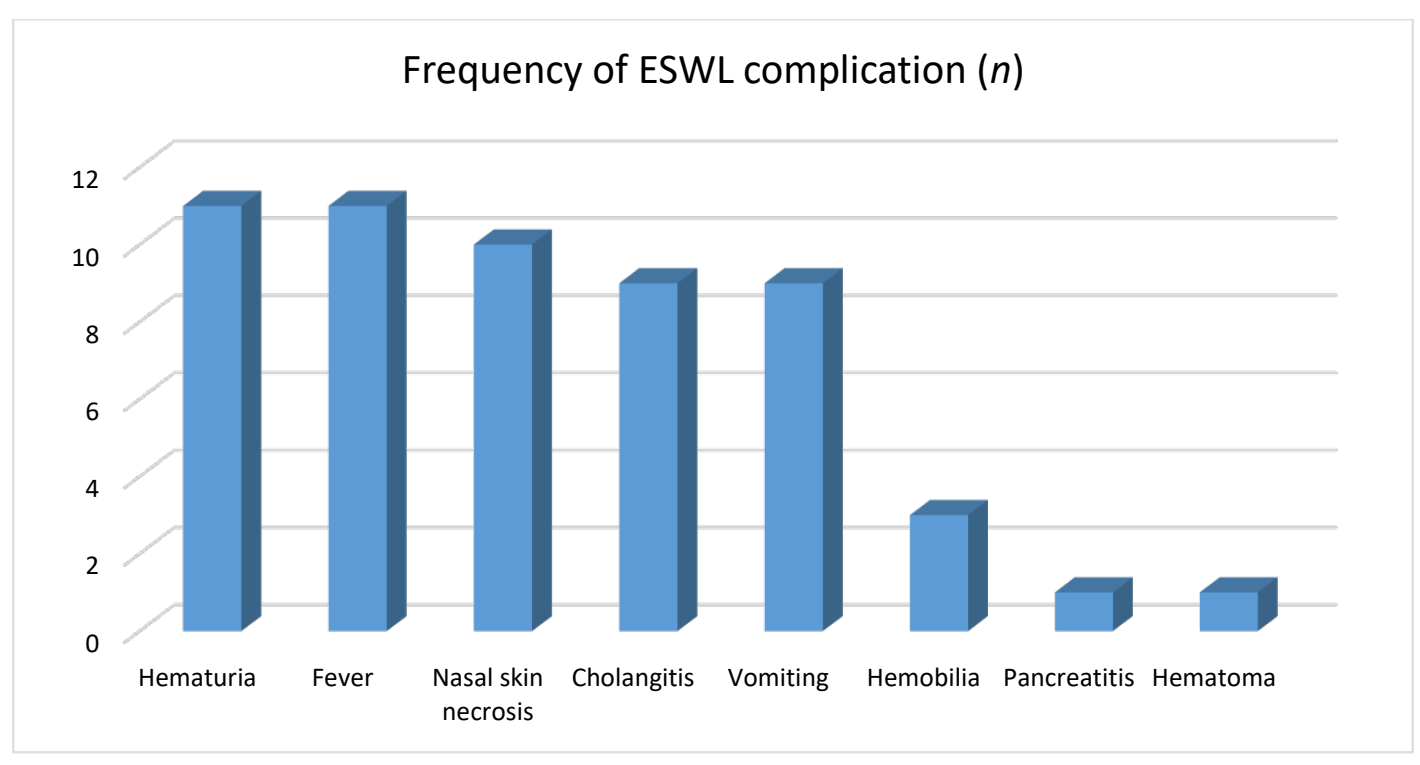

Figure 2: Common complications of extracorporeal shock wave lithotripsy (ESWL)

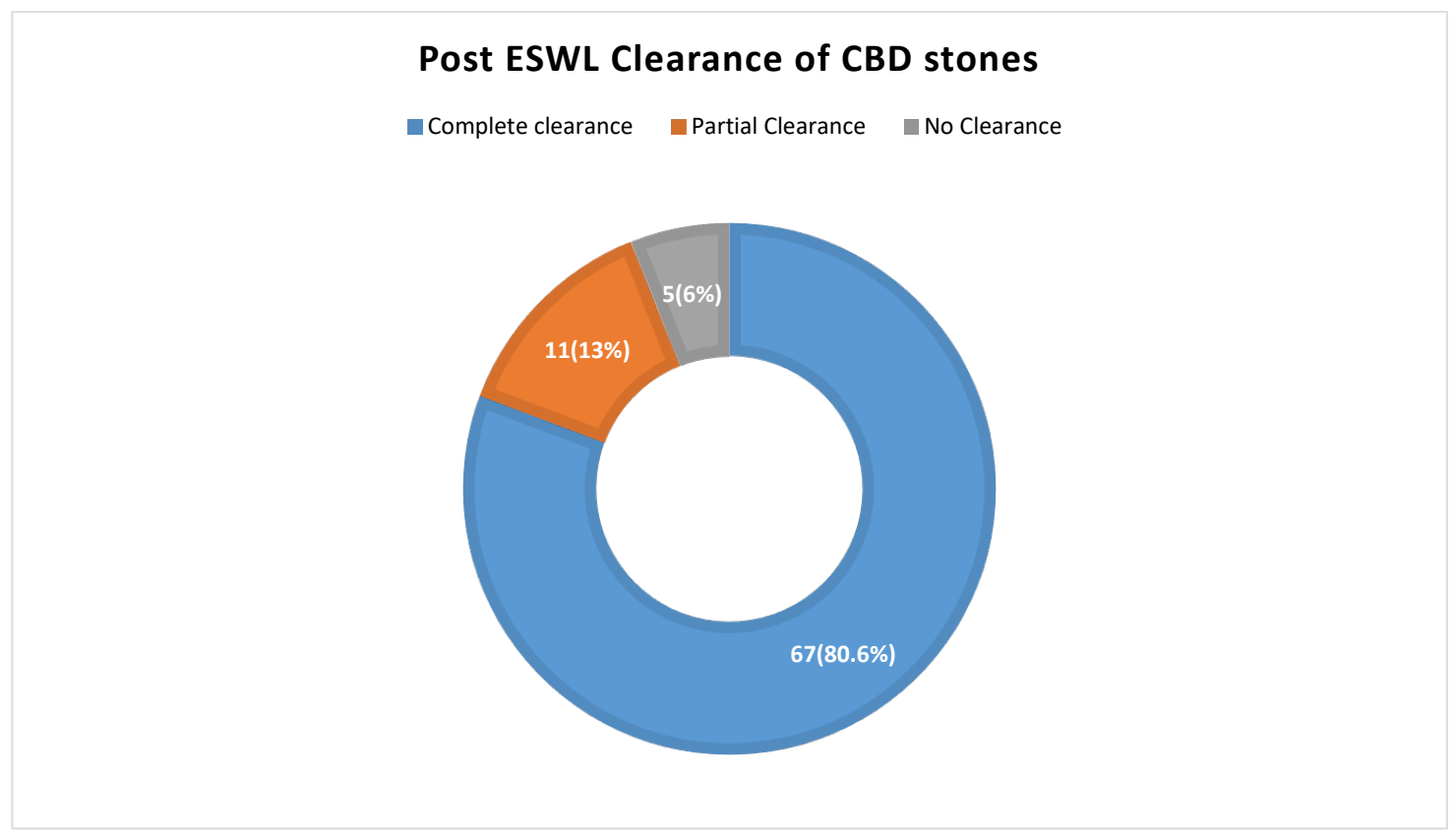

Figure 3: Rate of clearance of common bile duct (CBD) stones after extracorporeal shock wave lithotripsy (ESWL)

most of the patients do require a second ERCP for bile duct clearance. Recurrence of CBD stone after successful removal was frequently found in those patients who had prior gall stones as reported in previous studies; however, no association with recurrence and CBD diameter was observed in our study. Procedure-related complications can be avoided by performing ESWL on alternate days. Even if complications do occur, they are of mild intensity and get reversed rapidly without any sequelae. ${ }^{[6]}$
Surgical exploration of CBD for difficult-to-retrieve bile duct stones carries high mortality $(9 \%-10 \%)$, particularly in the elderly population. ${ }^{[3,7]}$ Contrary to this, ESWL is well tolerated, particularly in this age group. Our center is one of the largest regional centers for treating urolithiasis. ${ }^{[21]}$ Therefore, management cost is further reduced as the same machine is used by different specialties. Alternative therapeutic options include electrohydraulic and laser lithotripsy, but they are more invasive and require expensive 
equipment and fine expertise. These techniques have comparable outcomes at the cost of more frequent complications. ${ }^{[22,23]}$

\section{CONCLUSION}

The use of ESWL for difficult-to-retrieve CBD stones is a safe, effective and least invasive therapeutic option with desirable outcomes. It may be considered as a better alternative compared to surgical exploration of CBD in terms of cost-effectiveness, morbidity and hospital stay.

\section{Declarations}

The abstract of this research was published in Endoscopy journal in April-2018, which is included in the article with the permission of journal. The abstract detail is as follow: M. Manzoor ul Haque, N. Hassan Luck, A. Ali Tasneem. Safety and efficacy of extracorporeal shock wave lithotripsy for difficult-to-retrieve common bile duct stones: a ten year experience. Endoscopy 2018; 50 (04): 69-69. DOI: 1055/s-0038-1637232

\section{Conflict of Interest}

The authors have no financial conflict of interest.

\section{Acknowledgments}

We acknowledge our dedicated endoscopy technicians Abdur Rehman Khan, Iqbal Panjwani and Muhammad Bilal Sheikh for their immense contribution to all endoscopic procedures in the Department of Hepatogastroenterology, SIUT, Karachi, Pakistan.

\section{REFERENCES}

1. Seitz U, Bapaye A, Bohnacker S, Navarrete C, Maydeo A, Soehendra $\mathrm{N}$. Advances in therapeutic endoscopic treatment of common bile duct stones. World J Surg 1998; 22: 1133-44.

2. McHenry L, Lehman G. Difficult bile duct stones. Curr Treat Options Gastroenterol 2006; 9: 123-32.

3. Chaussy C, Brendel W, Schmiedt E. Extracorporeally induced destruction of kidney stones by shock waves. Lancet 1980; 2: 1265-8.

4. Binmoeller KF, Schafer TW. Endoscopic management of bile duct stones. J Clin Gastroenterol 2001; 32: 106-18.

5. Sauerbruch T, Stern M. Fragmentation of bile duct stones by extracorporeal shock waves. A new approach to biliary calculi after failure of routine endoscopic measures. Gastroenterology 1989; 96: 146-52

6. Tandan M, Reddy DNExtracorporeal shock wave lithotripsy for pancreatic and large common bile duct stones. World J Gastroenterol 2011; 17: 4365-71.
7. Tranter SE, Thompson MH. A prospective single-blinded controlled study comparing laparoscopic ultrasound of the common bile duct with operative cholangiography. Surg Endosc 2003; 17: 216-9.Jakobs R, Maier M, Kohler B, Riemann JF. Peroral laser lithotripsy of difficult intrahepatic and extrahepatic bile duct stones: laser effectiveness using an automatic stone-tissue discrimination system. Am J Gastroenterol 1996; 91: 468-73. Adamek HE, Maier M, Jakobs R, Wessbecher FR, Neuhauser T, Riemann JF. Management of retained bile duct stones: a prospective open trial comparing extracorporeal and intracorporeal lithotripsy. Gastrointest Endosc 1996; 44: 40-7.Neuhaus H, Zillinger C, Born P, Ott R, Allescher $\mathrm{H}$, Rösch T, et al. Randomized study of intracorporeal laser lithotripsy versus extracorporeal shock-wave lithotripsy for difficult bile duct stones. Gastrointest Endosc 1998; 47: 327-34.

8. Sackmann M, Holl J, Sauter GH, Pauletzki J, von Ritter C, Paumgartner G. Extracorporeal shock wave lithotripsy for clearance of bile duct stones resistant to endoscopic extraction. Gastrointest Endosc 2001; 53: 27-32.

9. Ellis RD, Jenkins AP, Thompson RP, Ede RJ. Clearance of refractory bile duct stones with extracorporeal shockwave lithotripsy. Gut 2000; 47: 728-31.

10. Kratzer W, Mason RA, Grammer S, Preclik G, Beckh K, Adler G. Difficult bile duct stone recurrence after endoscopy and extracorporeal shockwave lithotripsy. Hepatogastroenterology 1998; 45: 910-6.

11. Lomanto D, Fiocca F, Nardovino M, Grasso E, Lezoche E, Zarba Meli E, et al. ESWL experience in the therapy of difficult bile duct stones. Dig Dis Sci 1996; 41: 2397-403.

12. Testoni PA, Lella F, Masci E, Bagnolo F, Colombo E, Tittobello A. Combined endoscopic and extracorporeal shock-wave treatment in difficult bile duct stones: early and long-term results. Ital J Gastroenterol 1994; 26: 294-8.

13. Nicholson DA, Martin DF, Tweedle DE, Rao PN. Management of common bile duct stones using a second-generation extracorporeal shockwave lithotriptor. Br J Surg 1992; 79: 811-4.

14. Bland KI, Jones RS, Maher JW, Cotton PB, Pennell TC, Amerson JR, et al. Extracorporeal shock-wave lithotripsy of bile duct calculi. An interim report of the Dornier U.S. Bile Duct Lithotripsy Prospective Study. Ann Surg 1989; 209: 743-53.

15. Sauerbruch T, Stern M. Fragmentation of bile duct stones by extracorporeal shock waves. A new approach to biliary calculi after failure of routine endoscopic measures. Gastroenterology 1989;96:146-52.

16. Conigliaro R, Camellini L, Zuliani CG, Sassatelli R, Mortilla MG, Bertoni $\mathrm{G}$, et al. Clearance of irretrievable bile duct and pancreatic duct stones by extracorporeal shockwave lithotripsy, using a transportable device: effectiveness and medium term results. J Clin Gastroenterol 2006; 40: 213-9.

17. DiSario J, Chuttani R, Croffie J, Liu J, Mishkin D, Shah R, et al. Biliary and pancreatic lithotripsy devices. Gastrointest Endosc 2007; 65: 750-6.

18. Hussain M, Enormity of urolithiasis in Sindh province. J Pak Med Assoc. 2014; 64: 1337-8.

19. Neuhaus $H$, Zillinger $C$, Born $P$, Ott R, Allescher H, Rösch T, et al. Randomized study of intracorporeal laser lithotripsy versus extracorporeal shock-wave lithotripsy for difficult bile duct stones. Gastrointest Endosc 1998; 47: 327-34.

20. Hochberger J, Bayer J, May A, Mühldorfer S, Maiss J, Hahn EG, et al. Laser lithotripsy of difficult bile duct stones: results in 60 patients using a rhodamine $6 \mathrm{G}$ dye laser with optical stone tissue detection system. Gut 1998; 43: 823-9.

How to cite this article: Manzoor ul Haque M, Hassan Luck N, Ali Tasneem A, Mudassir Laeeq S, Mandhwani R, Hanif FM, et al. Safety and efficacy of extracorporeal shock wave lithotripsy for difficulttoretrieve common bile duct stones: A ten-year experience. J Transl Intern Med 2020; 8: 159-64. 